\title{
A comparison of serum biochemistry in ankylosing spondylitis, seronegative and seropositive rheumatoid arthritis
}

\author{
J. S. DIXON, H. A. BIRD, AND V. WRIGHT
}

From the Clinical Pharmacology Unit, Royal Bath Hospital, Harrogate, and the Rheumatism Research Unit, University Department of Medicine, General Infirmary, Leeds

SUMMARY The serum biochemistry of 31 patients with ankylosing spondylitis (AS) was compared with that of 80 patients with rheumatoid arthritis (RA) (ARA criteria), 30 of whom were negative for circulating rheumatoid factor and 50 of whom were 'seropositive'. All patients were selected because of moderate to severe disease activity. All 3 groups had distinctive biochemical profiles. Total serum sulphydryl and haemoglobin were particularly good discriminators between AS and RA. IgG, IgA, and acute-phase reactants complemented the sheep cell agglutination test in discriminating between seropositive RA and seronegative RA. In active AS a normal erythrocyte sedimentation rate was often seen in the presence of an abnormal C-reactive protein (CRP) and plasma viscosity.

Clinical epidemiology has advanced rheumatology by allowing the recognition of an increasing number of discrete arthropathies. Thus the concept of seronegative spondarthritides, once confused with rheumatoid arthritis (RA), is now recognised as a discrete entity on clinical, radiological, histological, and serological grounds. ${ }^{1}$ Since specific drugs therapy for these different conditions is likely to be based on a closer understanding of the underlying pathological processes, it is relevant to compare biochemical abnormalities occurring in different variants of polyarthritis.

Biochemical changes in the blood of patients with RA have been extensively investigated. ${ }^{2-6}$ Some of these changes have been claimed to be specific for this disease, e.g., low serum histidine. ${ }^{7}$ Such studies invariably use the criteria of the American Rheumatism Association for the selection of their patients. These criteria include the presence of circulating rheumatoid factor, but it is not mandatory for a diagnosis of RA to be made.

Between $23 \%^{8}$ and $40 \%$ of a rheumatoid population are 'seronegative', though the recent interest in 'hidden rheumatoid factor' emphasises that even

Accepted for publication 30 September 1980

Correspondence to Dr H. A. Bird, Clinical Pharmacology Unit (Rheumatism Research), Royal Bath Hospital, Cornwall Road, Harrogate HG1 2PS. 'seronegative' patients may still have abnormal circulating immune complexes. ${ }^{10-12}$ Seropositive RA (SPRA) has a poorer prognosis than seronegative RA (SNRA) ${ }^{13}$ and the spectrum of clinical symptoms may differ between these 2 variants. $^{914}$ However, the serum biochemistry in these variants, in relation to the nature and relevance of rheumatoid factor, has not been previously considered.

Of the seronegative spondarthritides ankylosing spondylitis (AS) is clinically a more distant relative of RA than Reiter's syndrome, psoriatic arthropathy, or colitic arthropathy. Although several biochemical abnormalities occur in AS (raised C-reactive protein (CRP) and elythrocyte sedimentation rate (ESR) ${ }^{15}$, raised immunoglobulins, ${ }^{16}$ and high total $\mathrm{Cu}$ with raised caeruloplasmin ${ }^{17}$ ), comprehensive surveys of other factors do not appear to have been undertaken. We know of no extensive studies in which biochemical assays have been performed concurrently in the same laboratory on groups of patients with these different diseases.

We have therefore compared a broad spectrum of biochemical variables in groups of patients with RA (ARA criteria), both seropositive and seronegative for circulating rheumatoid factor, and with AS (New York criteria ${ }^{18}$ ). All patients were selected because of moderate to severe disease activity. 


\section{Patients and methods}

\section{PATIENTS}

Rheumatoid arthritis. Fifty patients with RA (ARA criteria) were entered into the SPRA group, all having a persistent sheep cell agglutination test (SCAT) titre of $\leqslant 1 / 64$ over the month immediately preceding the blood sampling. Thirty RA patients (ARA criteria) were included in the SNRA group, all having a persistent SCAT titre of $\geqslant 1 / 8$. Patients with SCAT titres $1 / 16$ or $1 / 32$ were excluded from both groups. All 80 patients showed evidence of at least moderate disease activity as previously defined. ${ }^{6}$

Ankylosing spondylitis. Thirty-one patients with AS, all persistently seronegative for rheumatoid factor (SCAT titre $\geqslant 1 / 8$ ), were included in this group. All patients conformed to the New York criteria $^{18}$ and had active disease as judged by the presence of at least 2 of the following 6 criteria: (i) nocturnal pain; (ii) morning stiffness; (iii) pain and stiffness of more than 3 months' duration, not relieved by rest, in low back or dorsolumbar junction or in either or both buttocks; (iv) pain and stiffness in the thoracic region of more than 3 months' duration; (v) limitation of chest expansion; (vi) limitation in spinal anterior and lateral flexion and in spinal extension.

All patients. None of these 111 patients had previously received specific antirheumatic drug therapy (e.g., D-penicillamine or gold), and all took enteric coated aspirin alone for 2 weeks prior to the blood sampling to establish uniform conditions. A small number of the RA patients were on constant steroid therapy.

Table 1 Analytical details for biochemical variables

\begin{tabular}{ll}
\hline Variable & Method and Reference \\
\hline Serum histidine & Spectrofluorometric24 \\
Total serum sulphydryl & Spectrophotometric25 \\
Plasma viscosity & Capillary Viscometry26 \\
$\begin{array}{l}\text { C-reactive protein } \\
\text { Haptoglobin }\end{array}$ & Radial Immunodiffusion 27 \\
$\begin{array}{l}\text { Plasma gamma glutamyl } \\
\text { transpeptidase }\end{array}$ & Radial Immunodiffusion 27 \\
\hline
\end{tabular}

\section{ASSESSMENTS}

Six clinical assessments (pain score, Ritchie articular index, early morning stiffness, grip strength, joint size, and functional grade) were performed on all 80 RA patients at the time of blood sampling as previously described. ${ }^{6}$

A spectrum of 25 biochemical variables were measured in the two RA groups and 19 in the AS group-routine immunological tests being carried out on the RA groups only. Nonroutine assays are listed in Table 1 together with analytical methods.

One-way analysis of variance was used to compare the SNRA data with the SPRA data and to compare the SNRA results with the AS results.

\section{Results}

\section{SNRA COMPARED WITH SPRA}

The groups were similar in age (Table 2 ) and sex (F:M, SPRA 36:14, SNRA 25:5), thus allowing direct comparison of those variables known to be dependent on either of these factors. The clinical assessments (Table 2) were not significantly different between the SNRA and SPRA groups, thus suggesting approximately equivalent symptomology.

Results for the biochemical variables in the SPRA and SNRA groups are shown in Table 3. The considerable difference between the 2 groups in terms of RA latex, IgM, and IgA was to be expected and confirms the distinction based on SCAT data. Significantly higher values for plasma viscosity, CRP, and ESR were seen in the SPRA's together with significantly lower albumin and serum histidine values. All other biochemical variables failed to show a significant difference between the 2 groups.

\section{SNRA COMPARED WITH AS}

Data for the AS patients are presented in Table 4 and compared with the SNRA results. There were considerable differences in age and sex $(F: M$, SNRA 25:5, AS 6:25) between these 2 groups, with RA occurring predominantly in older females and AS in younger males. Thus in considering the other

Table 2 Comparison of clinical data for SPRA and SNRA

\begin{tabular}{|c|c|c|c|c|c|c|}
\hline \multirow[t]{2}{*}{ Variable } & & \multicolumn{2}{|c|}{$S N R A(n=30)$} & \multicolumn{2}{|c|}{$S P R A(n=50)$} & \multirow[t]{2}{*}{$F^{1}$} \\
\hline & & Mean & $S D$ & Mean & $S D$ & \\
\hline $\begin{array}{l}\text { Functional grade } 2 \\
\text { Joint size } \\
\text { Articular index } \\
\text { Pain score2 } \\
\text { Aspirin dose } \\
\text { Disease duration } \\
\text { Early morning stiffness } \\
\text { Age } \\
\text { Grip strength }\end{array}$ & $\begin{array}{l}\mathrm{mm} \\
\mathrm{yr} \\
\mathrm{min} \\
\mathrm{yr} \\
\mathrm{mmHg}\end{array}$ & $\begin{array}{c}1 \cdot 33 \\
55 \cdot 7 \\
23 \cdot 0 \\
3 \cdot 20 \\
8 \cdot 79 \\
8 \cdot 66 \\
161 \\
50 \cdot 6 \\
90 \cdot 2\end{array}$ & $\begin{array}{c}0.55 \\
4.67 \\
10 \cdot 7 \\
0.76 \\
3.99 \\
7.86 \\
199 \\
10 \cdot 7 \\
56 \cdot 6\end{array}$ & $\begin{array}{c}1 \cdot 70 \\
57 \cdot 1 \\
20 \cdot 7 \\
3 \cdot 04 \\
9 \cdot 48 \\
9 \cdot 95 \\
183 \\
51 \cdot 0 ! \\
90 \cdot 4\end{array}$ & $\begin{array}{c}0 \cdot 95 \\
5 \cdot 90 \\
12 \cdot 8 \\
0 \cdot 93 \\
3 \cdot 63 \\
7 \cdot 97 \\
214 \\
11 \cdot 0 \\
50 \cdot 0\end{array}$ & $\begin{array}{r}3 \cdot 70 \\
1 \cdot 21 \\
0.65 \\
0.60 \\
0.49 \\
0.48 \\
0.19 \\
0.02 \\
<0.01\end{array}$ \\
\hline
\end{tabular}

1 All nonsignificant. ${ }^{2}$ Scale 0-5. ${ }^{3}$ Number of tablets, maximum 12. 
Table 3 Comparison of biochemical data for SPRA and SNRA

\begin{tabular}{|c|c|c|c|c|c|c|}
\hline \multirow[t]{2}{*}{ Biochemical variable } & & \multicolumn{2}{|c|}{$S N R A(n=30)$} & \multicolumn{2}{|c|}{$S P R A(n=50)$} & \multirow[t]{2}{*}{$F$} \\
\hline & & Meran & $S D$ & Mean & $S D$ & \\
\hline IgA & IU.ml-1 & 211 & 94 & 318 & 158 & $10 \cdot 62^{* *}$ \\
\hline IgM & IU.ml-1 & 226 & 133 & 341 & 157 & $10 \cdot 41^{* *}$ \\
\hline Plasma viscosity & $\mathbf{c P}$ & $1 \cdot 88$ & $0 \cdot 12$ & 1.98 & $0 \cdot 16$ & $8 \cdot 90^{* *}$ \\
\hline Albumin & $\mathrm{gl}^{-1}$ & $41 \cdot 9$ & $3 \cdot 45$ & $40 \cdot 3$ & $2 \cdot 70$ & $5 \cdot 30^{*}$ \\
\hline Serum histidine & mg.dl-1 & $1 \cdot 32$ & $0 \cdot 30$ & $1 \cdot 18$ & $0 \cdot 26$ & $4 \cdot 86^{*}$ \\
\hline ESR & $\mathrm{mm} \cdot \mathrm{h}^{-1}$ & $47 \cdot 7$ & $26 \cdot 1$ & $60 \cdot 7$ & $25 \cdot 8$ & $4 \cdot 58^{*}$ \\
\hline WBC & $\times 10^{9} .1^{-1}$ & $7 \cdot 92$ & $2 \cdot 12$ & $8 \cdot 94$ & $2 \cdot 38$ & $3 \cdot 70$ \\
\hline Haptoglobin & gl. -1 & $3 \cdot 88$ & $1 \cdot 93$ & $4 \cdot 58$ & $1 \cdot 57$ & $3 \cdot 16$ \\
\hline $\mathrm{C} 4$ & mg. $\mathrm{dl}^{-1}$ & 47 & $14 \cdot 2$ & 40 & $17 \cdot 1$ & $2 \cdot 82$ \\
\hline Urea & $\mathrm{mmol} .1^{-1}$ & $5 \cdot 63$ & $1 \cdot 64$ & $5 \cdot 06$ & $1 \cdot 34$ & $2 \cdot 80$ \\
\hline GGTP & U.1-1 & $22 \cdot 7$ & $14 \cdot 3$ & $29 \cdot 6$ & $19 \cdot 9$ & $2 \cdot 69$ \\
\hline Platelet count & $\times 10^{9} .1^{-1}$ & 436 & 123 & 403 & 118 & $1 \cdot 35$ \\
\hline Globulin & gl. -1 & $35 \cdot 0$ & $4 \cdot 23$ & $36 \cdot 3$ & $4 \cdot 73$ & $1 \cdot 29$ \\
\hline Fibrinogen & g. $1^{-1}$ & $3 \cdot 01$ & 0.73 & $3 \cdot 21$ & 0.83 & $1 \cdot 12$ \\
\hline C3 & mg.dl-1 & 162 & $42 \cdot 2$ & 166 & $33 \cdot 8$ & 0.12 \\
\hline Bilirubin & $\mu \mathrm{mol} .1^{-1}$ & $6 \cdot 21$ & $2 \cdot 04$ & $6 \cdot 70$ & $2 \cdot 04$ & $1 \cdot 01$ \\
\hline Protein & g. $1^{-1}$ & $77 \cdot 6$ & $4 \cdot 33$ & $76 \cdot 7$ & $4 \cdot 20$ & 0.87 \\
\hline $\mathrm{Hb}$ & g. $\mathrm{dl}^{-1}$ & $11 \cdot 7$ & $1 \cdot 63$ & $11 \cdot 9$ & $1 \cdot 38$ & $0 \cdot 50$ \\
\hline SGOT & U. $1^{-1}$ & $18 \cdot 4$ & $16 \cdot 6$ & $16 \cdot 6$ & $11 \cdot 4$ & $0 \cdot 32$ \\
\hline Creatinine & $\mu \mathrm{mol} .1^{-1}$ & $78 \cdot 5$ & $22 \cdot 5$ & $77 \cdot 1$ & $17 \cdot 0$ & $0 \cdot 10$ \\
\hline IgG & IU.ml-1 & 187 & $67 \cdot 5$ & 190 & $51 \cdot 9$ & 0.04 \\
\hline Total sulphydryl & $\mu \mathrm{mol} .1^{-1}$ & 380 & $69 \cdot 8$ & 379 & $70 \cdot 8$ & $<0.01$ \\
\hline
\end{tabular}

***P<0.001. ** $P<0.01 .{ }^{*} P<0.05$.

Table 4 Comparison of SNRA data (Table 3) with data for $A S$

\begin{tabular}{|c|c|c|c|}
\hline \multirow[t]{2}{*}{ Variable } & \multicolumn{2}{|c|}{$A S(n=31)$} & \multirow[t]{2}{*}{$F$} \\
\hline & Mean & $S D$ & \\
\hline Age & $35 \cdot 8$ & 9.99 & $30 \cdot 05^{* *}$ \\
\hline $\mathrm{Hb}$ & $13 \cdot 6$ & $1 \cdot 60$ & $22 \cdot 06^{* *}$ \\
\hline Total sulphydryl & 460 & $81 \cdot 2$ & $16 \cdot 49^{* *}$ \\
\hline ESR & $26 \cdot 7$ & $18 \cdot 6$ & $14 \cdot 28^{* *}$ \\
\hline Creatinine & $96 \cdot 6$ & $23 \cdot 3$ & $9 \cdot 40^{* *}$ \\
\hline Disease duration & $13 \cdot 3$ & $7 \cdot 1$ & $5 \cdot 58^{*}$ \\
\hline Platelet count & 371 & $98 \cdot 2$ & $5 \cdot 07^{*}$ \\
\hline Haptoglobin & $4 \cdot 72$ & $1 \cdot 30$ & $3 \cdot 92$ \\
\hline Albumin & $43 \cdot 2$ & $2 \cdot 61$ & $2 \cdot 58$ \\
\hline Bilirubin & $7 \cdot 26$ & $2 \cdot 87$ & $2 \cdot 53$ \\
\hline GGTP & $27 \cdot 0$ & $15 \cdot 9$ & $1 \cdot 17$ \\
\hline Globulin & $33 \cdot 8$ & $4 \cdot 76$ & 0.94 \\
\hline CRP & $2 \cdot 27$ & $1 \cdot 84$ & 0.48 \\
\hline Urea & $5 \cdot 38$ & $1 \cdot 32$ & 0.44 \\
\hline WBC & $8 \cdot 15$ & $1 \cdot 58$ & $0 \cdot 24$ \\
\hline Serum histidine & $1 \cdot 35$ & 0.21 & 0.21 \\
\hline Alkaline phosphatase & $9 \cdot 59$ & $2 \cdot 89$ & $0 \cdot 16$ \\
\hline Plasma viscosity & $1 \cdot 87$ & $0 \cdot 14$ & $0 \cdot 13$ \\
\hline Protein & $77 \cdot 2$ & $4 \cdot 85$ & 0.08 \\
\hline SGOT & $17 \cdot \overline{7}$ & $5 \cdot 90$ & 0.06 \\
\hline Fibrinogen & 3.00 & 0.65 & $<0.01$ \\
\hline
\end{tabular}

$* * P<0.01$. * $P<0.05$.

variables it is necessary to allow for any dependence on age and sex. Haemoglobin, total serum sulphydryl, and creatinine were much higher (essentially normal) in the AS group, while ESR and platelet count were lower, and hence nearer normal, than in the SNRA group (Table 4). No other variable showed a significant difference between these 2 groups.
Table 5 Percentage of abnormal blood tests for $S P R A, S N R A$, and $A S$

\begin{tabular}{lrrrl}
\hline Biochemical variable & $S P R A$ & $S N R A$ & $A S$ & $\begin{array}{l}\text { High }(H) \text { or } \\
\text { low }(L)^{*}\end{array}$ \\
\hline Hb & & & & \\
WBC & 88 & 87 & 29 & $\mathrm{~L}$ \\
Platelet count & 12 & 7 & 0 & $\mathrm{H}$ \\
ESR & 6 & 14 & 6 & $\mathrm{H}$ \\
Plasma viscosity & 100 & 87 & 55 & $\mathrm{H}$ \\
Urea & 100 & 87 & 83 & $\mathrm{H}$ \\
Creatinine & 6 & 17 & 10 & $\mathrm{H}$ \\
Bilirubin & 0 & 0 & 0 & - \\
Alkaline phosphatase & 22 & 4 & 0 & $\mathrm{~L}$ \\
SGOT & 18 & 13 & $\mathrm{H}$ \\
Protein & 18 & 14 & 23 & $\mathrm{H}$ \\
GGTP & 22 & 29 & 30 & $\mathrm{H}$ \\
Total sulphydryl & 62 & 43 & 38 & $\mathrm{H}$ \\
Serum histidine & 88 & 90 & 40 & $\mathrm{~L}$ \\
CRP & 90 & 80 & 77 & $\mathrm{~L}$ \\
Albumin & 98 & 90 & 90 & $\mathrm{H}$ \\
Globulin & 4 & 7 & 0 & $\mathrm{~L}$ \\
Fibrinogen & 42 & 33 & 24 & $\mathrm{H}$ \\
Haptoglobin & 12 & 10 & 3 & $\mathrm{H}$ \\
RA Latex & 96 & 87 & 97 & $\mathrm{H}$ \\
IgG & 100 & 36 & ND & $\mathrm{H}$ \\
IgG & 46 & 46 & ND & $\mathrm{H}$ \\
IgM & 8 & 21 & ND & $\mathrm{L}$ \\
IgA & 100 & 79 & ND & $\mathrm{H}$ \\
IgA & 90 & 64 & ND & $\mathrm{H}$ \\
C3 & 2 & 11 & ND & $\mathrm{L}$ \\
C4 & 71 & 64 & ND & H \\
C4 & 50 & 70 & ND & H \\
\hline ND & 11 & 0 & ND & L \\
\hline
\end{tabular}

ND $=$ no data ${ }^{*}$ Compared with reported normal range. 6

The percentages of patients with abnormal values, as defined by comparison with reported normal ranges $^{6}$ in all 3 groups for each of the variables, are presented in Table 5. 


\section{Discussion}

SNRA COMPARED WITH SPRA

The higher levels of acute-phase reactants in the SPRA group suggest a more active disease in this group, since acute-phase proteins correlate well with disease activity. ${ }^{619}$ However, it should be noted that the 2 groups were clinically similar as shown by the clinical measurements. The high IgA and IgM levels among the SPRAs indicate greater immunological activity, possibly associated with rheumatoid factor. By contrast, no difference was seen in IgG concentration between SPRA and SNRA. It remains a possibility that $\mathrm{IgG} / \mathrm{IgG}$ complexes were present in the SNRA group. The low serum histidine in the SPRA group may contribute to the formation of rheumatoid factor ${ }^{20}$ or may be a more generalised reflection of enhanced disease activity.

In comparing SPRA with SNRA we found the mean values for several variables to be higher in the SPRA group even though they did not achieve a statistically significant identification. Such variables included haptoglobin and fibrinogen, in keeping with other raised acute phase proteins, alkaline phosphatase, and GGTP, indicating a greater degree of hepatic involvement. These results suggest greater systemic involvement in SPRA, though this may be localised to certain organs, since haemoglobin was depressed equally in both groups.

Total serum sulphydryl was the only other variable equally abnormal (low) in both groups (Tables 3 and 5). A rise in total serum sulphydryl levels in RA is relatively nonspecific. ${ }^{21}$ This rise may occur by direct interaction of drugs with serum proteins, and hence may be a temporary or false indication of disease improvement, occurring regardless of the presence or absence of rheumatoid factor. However, all the patients in the present study received aspirin alone for 2 weeks prior to bleeding, and hence the group comparisons are valid. The cause of low serum sulphydryl in RA is still not clear, though serum protein conformational abnormalities resulting in increased disulphide linkages constitute a strong possibility. Alternatively the low levels may be caused by circulating immune complexes in both SPRA and SNRA.

Although differences occurred in several biochemical variables between SPRA and SNRA, the clinical severity in the 2 groups, as defined by the 6 clinical assessments, was remarkably uniform (Table 2), possibly reflecting admission criteria to the study. However, equivalent clinical severity in the 2 groups was accompanied by comparable changes in serum sulphydryl and haemoglobin, while acutephase reactants and liver function tests were higher in the SPRA group. It therefore remains a possibility that acute phase reactants reflect increased systemic activity not reflected by the clinical symptoms, while the low levels of serum sulphydryl and perhaps haemoglobin are a direct consequence of the pathogenetic processes.

SNRA COMPARED WITH AS

In the case of AS the high incidence of raised acutephase reactants was essentially the same as for the RA groups, with the exception of ESR, which was raised in only $55 \%$ of cases (Table 5). Thus a third of the AS patients had raised plasma viscosity, CRP, and haptoglobin with normal ESR. Even when allowance is made for the age and sex dependence of the ESR in a normal population ${ }^{22}$ there appears to be a clear difference between ESR and other acute-phase reactants in AS. Since the patients were selected for disease activity, it may be that CRP or plasma viscosity are both preferrable to ESR as indices of disease activity.

Anaemia was far less frequent for AS than RA (Tables 4 and 5), but haemoglobin levels are sexdependent, the normal range for males being higher than that for females. ${ }^{22}$ Low total serum sulphydryl was also less frequent in AS and showed a significant difference when compared with that of RA. Age and sex dependence has been shown in one study on patients with $\mathrm{RA}^{3}$, but this is most likely linked with disease severity and duration. These differences in haemoglobin and total serum sulphydryl between AS and RA probably reflect underlying differences in disease pathogenesis. In addition the differences in serum sulphydryl levels lend support to the idea that their low levels in RA may be related to immune complexes. Furthermore the higher haemoglobin levels in the AS group may contribute towards the low ESR, and a high correlation has been demonstrated between these 2 variables in normal subjects ${ }^{22}$ and in $\mathbf{R A}$ and $\mathrm{AS}$ patients. $^{23}$

Our biochemical findings support the concept of SNRA, SPRA, and AS as discrete disease entities with their own individual biochemical profiles provided the disease is active. At the same time there are some similarities. Where a variable becomes abnormal in a disease, the trend to abnormality is always found in the same direction, whatever the disease. While SCAT by definition remains the best discriminator between SPRA and SNRA, IgA, IgM acute-phase reactants, and serum histidine may also have a role in confirming seropositivity. Serum sulphydryl and haemoglobin were the best discriminators between AS and RA, and the behaviour of these in relation to histidine and the ESR deserves further study, particularly in 
other seronegative spondarthritides. This may lead to the formulation of "biochemical diagnostic criteria' that might complement the existing guidelines suggested for RA by the American Rheumatism Association.

The Clinical Pharmacology Unit gratefully acknowledges the financial support of Roche Products Ltd.

The authors thank Dr M. E. Pickup for useful discussion; Mr J. R. Lowe for technical advice, Mrs P. A. Leatham for the clinical assessments, and Mrs D. K. Smith and Mrs R. H. Schofield for secretarial assistance.

\section{References}

1 Wright V, Moll J M H. Seronegative Polyarthritis. Amsterdam: Elsevier/North-Holland, 1976: 29-80.

2 Cockel R, Kendall M J, Becker J F, Hawkins C F. Serum biochemical values in rheumatoid disease. Ann Rheum Dis 1971; 30: 166-70.

3 Haataja M. Evaluation of the activity of rheumatoid arthritis. Scand J Rheumatol $1975 ; 4$ suppl. 7: 5-54.

4 Wilding P, Kendall M J, Holder R, Grimes J A, Farr M. The influence of drugs and disease activity on biochemical and haematological data in rheumatoid arthritis. Clin Chim Acta 1975; 64: 185-94.

5 Kendall M J. Biochemical studies in the assessment of rheumatic diseases. Clin Rheum Dis 1976; 2: 253-71.

${ }^{6}$ Dixon J S, Pickup M E, Lowe J R, Hallett C, Lee M R, Wright $\mathrm{V}$. Discriminatory indices of response of patients with rheumatoid arthritis treated with D-penicillamine. Ann Rheum Dis 1980; 39: 301-11.

7 Gerber D A, Gerber M G. Specificity of a low free serum hisidine concentration for rheumatoid arthritis. J Chron Dis 1977; 30: 115-27.

${ }^{8}$ Coste F, Delbarre F, Amor B, et al. Etude comparée de cent cas de polyarthrites (rheumatoides?) séronégatives et de cent cas de polyarthrites rheumatoides seropositives. Sem Hop Paris 1968; 44 : 777.

9 Morgan E S, Atwater E C. A comparison of patients with seropositive and seronegative rheumatoid arthritis. Med Clin North Am 1968; 52: 533-8.

10 Allen J C, Kunkel H G. Hidden rheumatoid factors with specificity for native $\gamma$ globulins. Arthritis Rheum 1966; 9: 785-6.

11 Bluestone R, Goldberg L S, Cracchiolo A. Hidden rheumatoid factors in seronegative nodular rheumatoid arthritis. Lancet 1969 ; ii: $878-9$.

12 Cracchiolo A, Bluestone R, Goldberg L S. Hidden antiglobulins in rheumatoid disorders. Clin Exp Immunol 1970; 119: 295-300.

13 Cats A, Hazevoet M. Significance of positive test for rheumatoid factor in the prognosis of rheumatoid arthritis. Ann Rheum Dis 1970; 29: 254-9.

14 Bland J H, Brown E W. Seronegative and seropositive rheumatoid arthritis. Clinical, radiological and biochemical differences. Ann Intern Med 1964; 60: 88-94.

15 Cowling P, Ebringer R, Cawdell D, Ishii M, Ebringer A. C-reactive protein, ESR, and klebsiella in ankylosing spondylitis. Ann Rheum Dis 1980; 39: 45-9.

16 Veys E M, Van Leare M. Serum IgG, IgM and IgA levels in ankylosing spondylitis. Ann Rheum Dis 1973; 32: 493-6.

17 Koskelo P, Kekki M, Virkkunen M, Lassus A, Somer T. Serum ceruloplasmin concentration in rheumatoid arthritis, ankylosing spondylitis, psoriasis and sarcoidosis. Acta Rheum Scand 1966; 12: 261-6.

18 Bennett P H, Wood P H N, eds. Population Studies of the Rheumatic Diseases (Proceedings of the 3rd International Symposium, New York, 1966). Amsterdam: Excerpta Medica, 1968: 456.

19 McConkey B, Crockson R A, Crockson A P, Wilkinson A R. The effects of some anti-inflammatory drugs on the acute phase proteins in rheumatoid arthritis. $Q \mathrm{~J} \mathrm{Med}$ 1973; 42: 785-91.

20 Gerber D A. Inhibition of denaturation of human gamma globulin by a mixture of L-histidine, L-cystine, and copper, and its clinical implication in rheumatoid arthritis. Arthritis Rheum 1976; 19: 593-601.

21 Pickup M E, Dixon J S, Bird H A. On the effects of antirheumatic drugs on protein sulphydryl reactivity in human serum. J Pharm Pharmacol 1980; 32: 301-2.

22 Bottiger L E, Svedberg C A. Normal erythrocyte sedimentation rate and age. $\mathrm{Br} \mathrm{Med} J$ 1967; ii: 85-7.

23 Dixon J S. Unpublished data.

24 Gerber D A. Determination of histidine in serum with $o$-phthaldialdehyde. Anal Biochem 1970; 34: 500-4.

25 Gerber D A, Cohen N, Giustra R. The ability of nonsteroid anti-inflammatory compounds to accelerate a disulphide interchange reaction of serum sulphydryl groups and 5,5'-dithiobis (2-nitrobenzoate). Biochem Pharmacol 1967; 16: 115-23.

26 Harkness $J$. The viscosity of human blood plasma: its measurement in health and disease. Biorheology 1971, 8: 171-93.

27 Mancini G, Carbonara A D, Heremans J F. Immunochemical quantitation of antigens by single radial immunodiffusion. Immunochemistry 1965; 2: 235-54.

28 Jacobs W L W. A colourimetric assay for $\gamma$-glutamyltranspeptidase. Clin Chim Acta 1971; 31: 175-9. 